\section{(2) OPEN ACCESS}

\title{
Long-term survival benefit of ramipril in patients with acute myocardial infarction complicated by heart failure
}

\author{
Jianhua Wu (1) , ${ }^{1,2}$ Alistair S Hall, ${ }^{3}$ Chris P Gale, ${ }^{4}$ on behalf of the AIREX Study \\ Investigators
}

- Additional material is published online only. To view, please visit the journal online (http://dx.doi.org/10.1136 heartjnl-2020-316823)

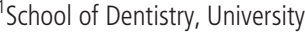
of Leeds, Leeds, UK ${ }^{2}$ Leeds Institute for Data Analytics, University of Leeds, Leeds, UK

${ }^{3}$ Medicine, Leeds Institute for Genetics Health and Therapeutics, Leeds, UK ${ }^{4}$ Leeds Institute for Cardiovascular and Metabolic Medicine, University of Leeds, Leeds, UK

Correspondence to Professor Alistair S Hall, Medicine, Leeds Institute for Genetics Health and Therapeutics, Leeds LS1 3EX UK; a.s.hall@leeds.ac.uk

Received 13 March 2020 Revised 29 April 2020 Accepted 30 April 2020 Published Online First 15 January 2021

\begin{abstract}
Aims ACE inhibition reduces mortality and morbidity in patients with heart failure after acute myocardial infarction (AMI). However, there are limited randomised data about the long-term survival benefits of ACE inhibition in this population.

Methods In 1993, the Acute Infarction Ramipril Efficacy (AIRE) study randomly allocated patients with AMI and clinical heart failure to ramipril or placebo. The duration of masked trial therapy in the UK cohort (603 patients, mean age $=64.7$ years, 455 male patients) was 12.4 and 13.4 months for ramipril $(n=302)$ and placebo $(n=301)$, respectively. We estimated life expectancy and extensions of life (difference in median survival times) according to duration of follow-up (range 0-29.6 years).
\end{abstract}

Results By 9 April 2019, death from all causes occurred in 266 (88.4\%) patients in placebo arm and $275(91.1 \%)$ patients in ramipril arm. The extension of life between ramipril and placebo groups was 14.5 months $(95 \% \mathrm{Cl} 13.2$ to 15.8). Ramipril increased life expectancy more for patients with than without diabetes (life expectancy difference 32.1 vs 5.0 months), previous AMI (20.1 vs 4.9 months), previous heart failure (19.5 vs 4.9 months), hypertension (16.6 vs 8.3 months), angina ( 16.2 vs 5.0 months) and age $>65$ years ( 11.3 vs 5.7 months). Given potential treatment switching, the true absolute treatment effect could be underestimated by $28 \%$.

Conclusion For patients with clinically defined heart failure following AMI, ramipril results in a sustained survival benefit, and is associated with an extension of life of up to 14.5 months for, on average, 13 months treatment duration.

\section{INTRODUCTION}

Survival following acute myocardial infarction (AMI) remains a key objective for healthcare professionals and governments throughout the globe. Despite major advances in the emergency treatment and secondary prevention of AMI, a substantial proportion of patients with AMI develop heart failure, ${ }^{1}$ which in turn is associated with high morbidity, mortality and healthcare expenditure. ${ }^{2-4}$

Moreover, therapeutic inhibition of ACE has become an established strategy in the care of patients with AMI and heart failure. ${ }^{5}$ ACE inhibition reduces death and disease in patients with left ventricular systolic dysfunction, and coronary artery disease. ${ }^{6-9}$ In the Acute Infarction Ramipril
Efficacy (AIRE) study, ACE inhibition at an average follow-up time of 15 months after randomisation significantly reduced all-cause mortality, and continued to confer a survival benefit at 3 years following study closure in the AIRE Extension (AIREX) study. $^{10}{ }^{11}$ Further placebo-controlled survival studies testing the efficacy of ACE inhibition in patients with AMI and clinical heart failure are unlikely because withholding a treatment of accepted clinical value would be unethical. Therefore, in the AIRE survival (AIRE-S) study, we aimed to assess the long-term (29.6 years after randomisation) magnitude of impact on length of survival observed after treatment with ramipril (target dose $5 \mathrm{mg}$ twice daily) when compared with placebo.

\section{METHODS}

\section{Patients and design}

The rationale, design, organisation, outcome definitions and results of the AIRE study have been published previously. ${ }^{10} 12$ This was an independent, multinational, multicentre, double-blind, randomised, placebo-controlled, parallel-group investigation into the potential benefits from treatment with the lipophilic ACE inhibitor ramipril (target dose $10 \mathrm{mg} /$ day) following AMI complicated by clinical evidence of heart failure. When the trial was conducted, in 1993, all patients had an ECG and cardiac enzyme confirmation of AMI, and also evidence of transient or persisting heart failure as judged by the attending physician (chest X-ray evidence of left ventricular failure, or auscultatory evidence of pulmonary oedema, or a third heart sound in the presence of persistent tachycardia), usually sufficient to justify diuretic or vasodilator therapy. Patients were excluded if they had evidence of clinical instability, contraindications to the use of ACE inhibitor therapy, heart failure of primary valvular or congenital origin or overt heart failure deemed to require treatment with an open-label ACE inhibitor. After applying these entry criteria to consecutive patients admitted to the UK centres (30 centres), 44\% of patients approached declined to give their consent to take part in the study. All 603 of the remaining patients were then randomised by telephone to receive masked treatment with either ramipril (titrated over 4 days to $5 \mathrm{mg}$ twice daily) or a matching placebo. Treatment was started between 2 and 9 days after the onset of AMI. Patients initially received either 1.25 or $2.5 \mathrm{mg}$ ramipril or 
Table 1 Duration of treatment with blinded trial medication subdivided by cause for cessation of treatment

\begin{tabular}{|c|c|c|c|c|}
\hline Reason for stopping & Allocated placebo $(n=301)$ & Allocated ramipril $(n=302)$ & $P$ value & Duration of ramipril/placebo (months) \\
\hline Intolerance & $28(9.3 \%)$ & $66(21.9 \%)$ & $<0.001$ & 3.55 \\
\hline Intercurrent disease & $11(3.7 \%)$ & $13(4.3 \%)$ & NS & 9.02 \\
\hline Patient refusal & $10(3.3 \%)$ & $28(9.3 \%)$ & 0.004 & 3.19 \\
\hline Failure to attend & $3(1.0 \%)$ & $5(1.7 \%)$ & NS & 2.73 \\
\hline Death & $34(11.0 \%)$ & $19(6.3 \%)$ & 0.032 & 5.51 \\
\hline Severe HF & $41(13.6 \%)$ & $22(7.3 \%)$ & 0.012 & 5.05 \\
\hline Other reasons & $50(16.6 \%)$ & $31(10.3 \%)$ & 0.022 & 7.22 \\
\hline AIRE close & $146(48.5 \%)$ & $139(46.0 \%)$ & NS & 21.00 \\
\hline All patients & $301(100 \%)$ & $302(100 \%)$ & & 12.87 \\
\hline
\end{tabular}

The decision as to use of ACE inhibitor treatment beyond 28 February 1993 was at the discretion of the attending clinician in the presence of ongoing blinding to randomised treatment allocation. The reasons for discontinuation are not mutually exclusive.

AIRE, Acute Infarction Ramipril Efficacy; HF, heart failure; NS, not significant.

identical placebo twice daily, titrating to a maintenance dose of either 2.5 or $5 \mathrm{mg}$ twice daily. No prerandomisation assessment of tolerance was undertaken. Thus, the trial set out to test the specific clinical strategy of the intention-to-treat patients with the appropriate blinded trial therapy. As a result of not excluding patients shown to be intolerant to treatment, $86.4 \%$ of patients were taking ramipril (2.5 $\mathrm{mg}$ twice daily, $7.9 \%$ and $5 \mathrm{mg}$ twice daily, $78.5 \%)$ and $94.7 \%$ were taking placebo $(2.5 \mathrm{mg}$ twice daily, $4.2 \%$ and $5 \mathrm{mg}$ twice daily, 90.5\%) when discharged from hospital. At the time of the AIRE study close (midnight on 28 February 1993), double-bind, randomised treatment was still being taken by $46 \%$ and $48.5 \%$ of patients randomised to receive ramipril and placebo, respectively (table 1 ). Thereafter, the use of ACE inhibitor therapy was open label and guided by clinical discretion based on the evidence base available at that time. Clinicians were still blinded to randomised treatment allocation at that time and also for the following 6 months beyond study close.

For the AIRE-S study, we accessed the National Health Service Spine on 9 April 2019 to obtain information on all-cause

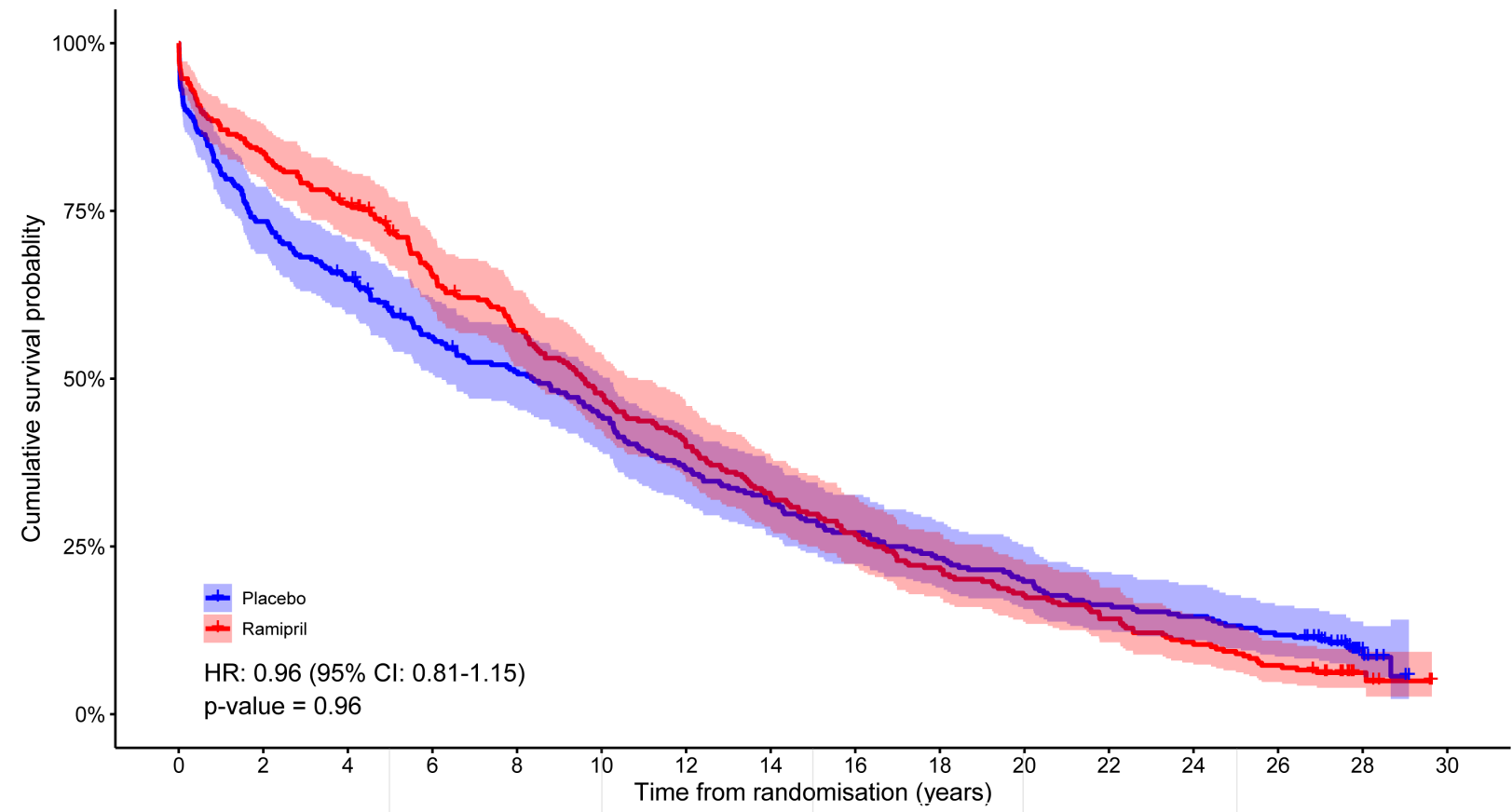

\begin{tabular}{|c|c|c|c|c|c|c|c|c|c|c|c|c|c|c|}
\hline \multicolumn{15}{|c|}{ Number at risk } \\
\hline Placebo & 301 & 221 & 194 & 163 & 147 & 128 & 105 & 91 & 78 & 67 & 57 & 47 & 42 & 34 \\
\hline Ramipril & 302 & 253 & 228 & 190 & 165 & 137 & 115 & 94 & 77 & 63 & 51 & 41 & 30 & 21 \\
\hline \multicolumn{3}{|c|}{ RMST (months, 95\% Cl) } & \multicolumn{2}{|c|}{ 5-year } & \multicolumn{3}{|c|}{ 10-year } & \multicolumn{3}{|c|}{ 15-year } & \multicolumn{2}{|c|}{ 20-year } & \multicolumn{2}{|c|}{ 25-year } \\
\hline \multicolumn{3}{|l|}{ Ramipril } & \multicolumn{2}{|c|}{$49.2(46.9-51.5)$} & \multicolumn{3}{|c|}{$84.9(80.0-89.8)$} & \multicolumn{3}{|c|}{$107.8(100.4-115.2)$} & \multicolumn{2}{|c|}{$121.6(112.2-131.0)$} & \multicolumn{2}{|c|}{$129.6(118.8-140.5)$} \\
\hline \multicolumn{3}{|c|}{ Ramipril - Placebo } & \multicolumn{2}{|c|}{$5.6(2.1-9.0)$} & \multicolumn{3}{|c|}{$10.0(2.6-17.4)$} & \multicolumn{3}{|c|}{$11.6(0.7-22.6)$} & \multicolumn{2}{|c|}{$10.9(-3.0-24.8)$} & \multicolumn{2}{|c|}{$9.4(-6.8-25.5)$} \\
\hline
\end{tabular}

Figure 1 Kaplan-Meier survival curves for patients randomly allocated to receive placebo (301 patients) or ramipril (302) patients. Restricted mean survival time (RMST) for placebo and ramipril arms and their differences were presented in months with $95 \% \mathrm{Cl}$ at 5, 10, 15, 20 and 25 years. 

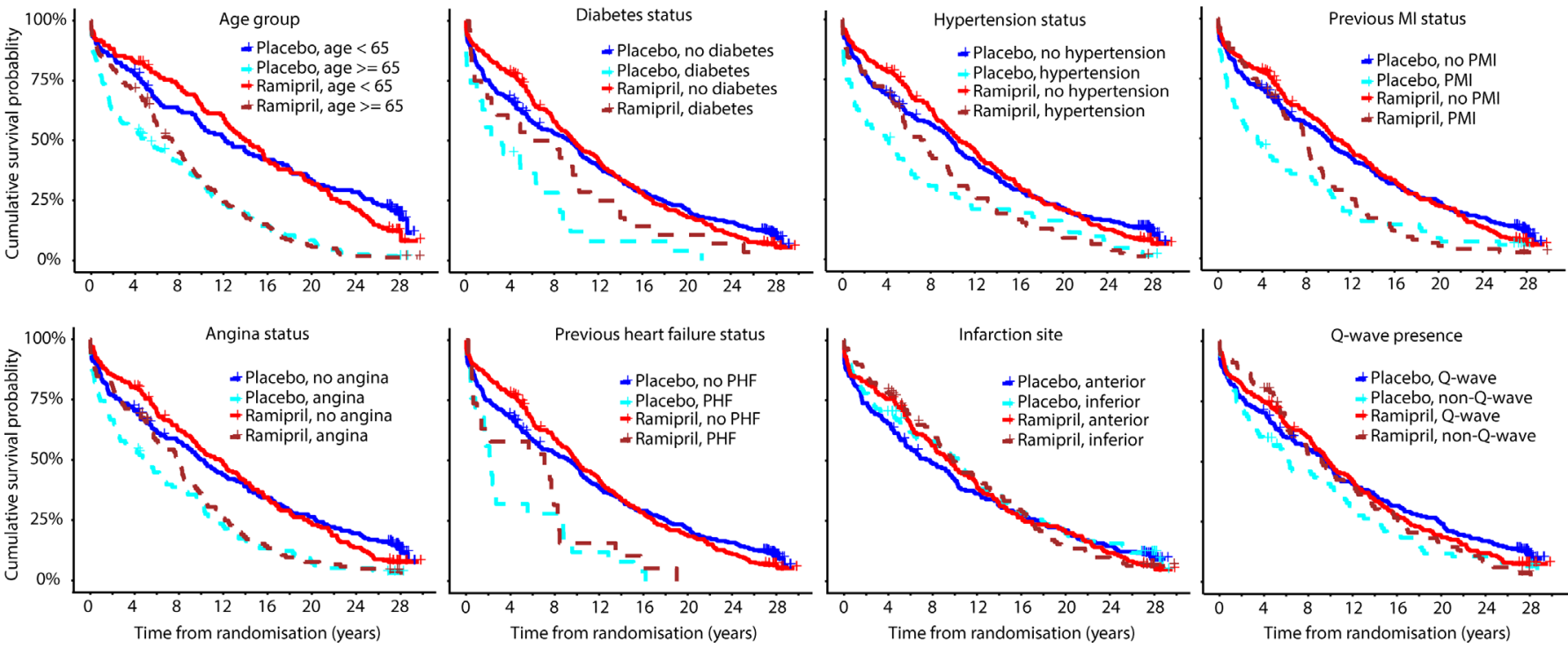

Figure 2 Kaplan-Meier survival curves for patients randomly allocated to receive placebo (301 patients) or ramipril (302) patients, by subgroups. PMI, previous myocardial infarction, PHF, previous heart failure.

mortality for all UK participants. For AIRE study, an independent adjudicating panel acted as the overall ethical supervisory body and had access to the randomisation code. ${ }^{10}$ For AIREX study, 603 patients in the UK provided informed consent. Ethical permission was obtained from each centre, and mortality information was accessed through Office for National Statistics. ${ }^{11}$

A Life expectancy difference
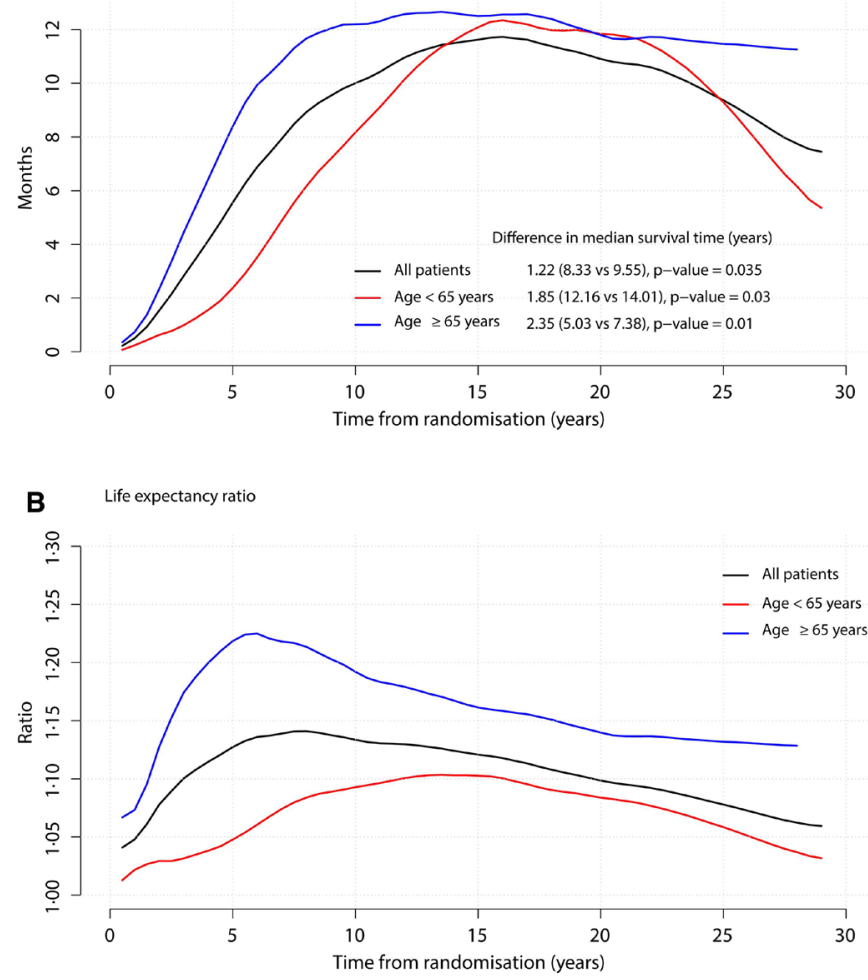

Figure 3 Life expectancy difference (A) and life expectancy ratio (B) for all patients and those under and above the median age of 65 years.

\section{Statistical analyses}

The statistical significance for differences in the proportion of patients with differing reasons for cessation of randomised treatment were compared for placebo and ramipril groups using the Fisher's exact test. Kaplan-Meier survival curves were constructed and clinical subgroups were compared using the log rank test where the survival curves did not cross over. Restricted mean survival time (RMST) was used to measure the average survival time from randomisation to any follow-up time point. ${ }^{1314}$ RMST was chosen to model the data because the survival curves of the ramipril and placebo groups crossed over during follow-up and the HR was time dependent. A superficial interpretation is that after a while, ramipril may start to become hazardous. The RMST is equivalent to the area under the Kaplan-Meier curve from the randomisation up to that time point, and can be interpreted as life expectancy. ${ }^{15}$ Life expectancy difference (LED, the difference between the RMSTs) and life expectancy ratio (LER, the ratio between the RMSTs) were calculated for each time point to quantify the treatment effects of ramipril, and may be interpreted as absolute and relative gains or losses in life expectancy. The RMST was calculated separately for ramipril and placebo groups using numerical integration of the modelled survival curve obtained using a flexible parametric model adjusted for the baseline patient characteristics (age, sex, medical history and type of AMI).

The median lifetime, represented by the median survival time, was estimated from the Kaplan-Meier curves. Extension of life was calculated by subtraction of the two median lifetimes for the ramipril and placebo groups. The non-parametric two-sample procedure for comparing survival quantiles was used to compare the difference in the median survival times for patients allocated to placebo or ramipril. ${ }^{16}$

Given the original AIRE study demonstrated a substantial survival benefit of ramipril treatment for patients with AMI and heart failure at the study closure, it is likely that patients in placebo group may have subsequently been switched to receive ramipril treatment. Therefore, the counterfactual survival times, due to treatment switching after study closure, were estimated by fitting a rank preserving structural failure time model. ${ }^{17} 18$ This was undertaken for a combination of hypothetical scenarios 
Table 2 Life expectancy difference, life expectancy ratio and median lifetime difference for patients randomly allocated to placebo or ramipril arms, by baseline patient characteristic

\begin{tabular}{|c|c|c|c|c|c|}
\hline \multirow[b]{2}{*}{ Subgroup } & \multicolumn{2}{|c|}{ No of patients } & \multirow{2}{*}{$\begin{array}{l}\text { Life expectancy difference } \\
\text { (months) }(95 \% \mathrm{Cl})\end{array}$} & \multirow{2}{*}{$\begin{array}{l}\text { Life expectancy ratio } \\
(95 \% \mathrm{Cl})\end{array}$} & \multirow{2}{*}{$\begin{array}{l}\text { Difference of median } \\
\text { lifetime (months) }(95 \% \mathrm{Cl})\end{array}$} \\
\hline & Placebo & Ramipril & & & \\
\hline \multicolumn{6}{|l|}{ Sex } \\
\hline Male & 230 & 225 & $10.4(-9.8$ to 30.5$)$ & $1.08(0.93$ to 1.26$)$ & 18.1 (16.7 to 19.6$)$ \\
\hline Female & 71 & 77 & $-0.3(-33.1$ to 32.6$)$ & 1.00 (0.76 to 1.32$)$ & $-0.9(-3.7$ to 1.9$)$ \\
\hline \multicolumn{6}{|l|}{ Age (years) } \\
\hline$<65$ & 137 & 136 & $5.7(-22.5$ to 33.8$)$ & 1.03 (0.88 to 1.22 ) & 22.2 (20.4 to 24.1 ) \\
\hline$\geq 65$ & 163 & 166 & 11.3 (-6.7 to 29.2$)$ & 1.13 (0.93 to 1.37 ) & 28.2 (26.2 to 30.2 ) \\
\hline \multicolumn{6}{|l|}{ Previous MI } \\
\hline No & 228 & 222 & $4.9(-15.7$ to 25.5$)$ & 1.04 (0.89 to 1.20$)$ & 7.7 (6.5 to 8.8$)$ \\
\hline Yes & 73 & 80 & $20.1(-7.5$ to 47.8$)$ & 1.25 (0.91 to 1.71$)$ & 50.8 (49.0 to 52.6 ) \\
\hline \multicolumn{6}{|l|}{ Hypertension } \\
\hline No & 237 & 219 & 8.3 (-11.8 to 28.5$)$ & 1.06 (0.92 to 1.23$)$ & 9.1 (8.0 to 10.2 ) \\
\hline Yes & 64 & 83 & $16.6(-14.6$ to 47.7$)$ & 1.19 (0.85 to 1.68$)$ & 36.1 (34.2 to 38.1 ) \\
\hline \multicolumn{6}{|l|}{ Diabetes mellitus } \\
\hline No & 274 & 274 & $5.0(-13.3$ to 23.3$)$ & 1.04 (0.90 to 1.19$)$ & 4.3 (3.0 to 5.5$)$ \\
\hline Yes & 27 & 28 & 32.1 (-6.8 to 71.0$)$ & 1.54 (0.90 to 2.61$)$ & 43.3 (40.6 to 46.0 ) \\
\hline \multicolumn{6}{|c|}{ History of angina } \\
\hline No & 199 & 191 & $5.0(-17.5$ to 27.4$)$ & 1.03 (0.89 to 1.21$)$ & 21.7 (20.4 to 23.0$)$ \\
\hline Yes & 102 & 111 & $16.2(-7.3$ to 39.7$)$ & 1.19 (0.92 to 1.53$)$ & 35.1 (33.3 to 36.9 ) \\
\hline \multicolumn{6}{|l|}{ Previous HF } \\
\hline No & 276 & 283 & $4.9(-13.3$ to 23.1$)$ & 1.04 (0.91 to 1.19$)$ & 6.6 (5.3 to 7.9$)$ \\
\hline Yes & 25 & 19 & 19.5 (-15.6 to 54.7$)$ & 1.38 (0.77 to 2.46$)$ & 59.5 (56.6 to 62.5$)$ \\
\hline \multicolumn{6}{|c|}{ Type of infarction } \\
\hline Anterior & 176 & 176 & $8.7(-14.3$ to 31.7$)$ & 1.07 (0.89 to 1.28$)$ & 21.4 (19.9 to 22.9$)$ \\
\hline Inferior & 109 & 119 & 0.2 (-27.5 to 27.8$)$ & 1.00 (0.82 to 1.23$)$ & $-5.6(-7.3$ to -3.8$)$ \\
\hline Q-wave & 205 & 207 & $-2.3(-23.8$ to 19.3$)$ & 0.98 (0.84 to 1.15$)$ & 3.1 (1.8 to 4.4$)$ \\
\hline Non-Q-wave & 83 & 89 & 23.2 (-6.5 to 52.8$)$ & 1.22 (0.94 to 1.57$)$ & 35.8 (33.3 to 38.2 ) \\
\hline All patients & 301 & 302 & 7.4 (-10.0 to 24.9$)$ & 1.06 (0.93 to 1.21$)$ & 14.5 (13.2 to 15.8$)$ \\
\hline
\end{tabular}

$\mathrm{HF}$, heart failure; $\mathrm{MI}$, myocardial infarction.

including a range of proportions of patients in the placebo arm switching to the treatment and a range of proportions of patients in the ramipril arm switching to the placebo arm (which was based on data for those patients who refused treatment or had drug intolerances in the AIRE study in table 1). Patients in the placebo arm were assumed to switch to ramipril or another ACE inhibitor within 5 years after the study closure with uniform distribution of switching times and were assumed a treatment effect equal to that of the ramipril group. Adjusted HRs were estimated for each scenario every 5 years from the time of randomisations for 25 years, and 95\% CIs estimated through bootstrapping.

All analyses were performed based on intention to treat except for modelling the hypothetical treatment switching. Statistical analyses and data management were performed in R V.3.5.1.

\section{RESULTS}

The survival status at 27.6 years after close of the AIRE study was ascertained for all 603 patients recruited within the UK. As described previously, the two groups were well matched with a mean age of 64.7 (SD 9.6) years (online supplementary table 1). Blinded trial medication was taken by patients for an average of 12.9 months (ramipril 12.4 months; placebo 13.4 months) (table 1). Treatment withdrawal due to intolerance $(21.9 \%$ vs $9.3 \%, \mathrm{p}<0.001)$ and patient refusal $(9.3 \%$ vs $3.3 \%, \mathrm{p}=0.002)$ was higher in the ramipril group, and higher as a result of death
(11.0\% vs $6.3 \%, \mathrm{p}=0.021)$ or development of severe clinical heart failure $(13.6 \%$ vs $7.3 \%, p=0.008)$ in the placebo group.

At the time of censorship (9 April 2019), there were 18 (2.9\%) patients who were lost to follow-up. In total, there were 541 $(89.7 \%)$ deaths (266 deaths in placebo group and 275 deaths in ramipril group) over a median time of death of 7.9 years (range 0.0-28.7 years) after recruitment, representing 4945.2 patientyears follow-up, between 0 and 29.6 years of study follow-up. Survival at the end of study follow-up was not different between the ramipril and placebo groups (HR 0.96, 95\% CI 0.81 to 1.15 , figure 1) because more-or-less all patients had died at the end of follow-up. Similar trends were evident when the survival was stratified by patient characteristics (figure 2 ).

The median survival time was 8.3 years (95\% CI 6.2 to 10.2 years) for placebo group and 9.6 years (95\% CI 8.3 to 10.9 years) for ramipril group. The extension of life between ramipril and placebo groups, measured by the difference in median survival time, was 14.5 (95\% CI 13.2 to 15.8 ) months. The survival curves crossed at 14 years from the time of randomisation and the life expectancy difference between ramipril and placebo groups was greatest at about 15 years from the time of randomisation (LED 11.6 months, 95\% CI 0.7 to 22.6) (figure 3). The magnitude of the LER was largest at around 7 years from the time of randomisation $(1.14,95 \%$ CI 1.05 to 1.23$)$. At the end of follow-up, the LED and LER between ramipril and placebo was 7.4 months (95\% CI -10.0 to 24.9$)$ and 1.06 (95\% CI 0.93 to 1.21$)$, respectively. 

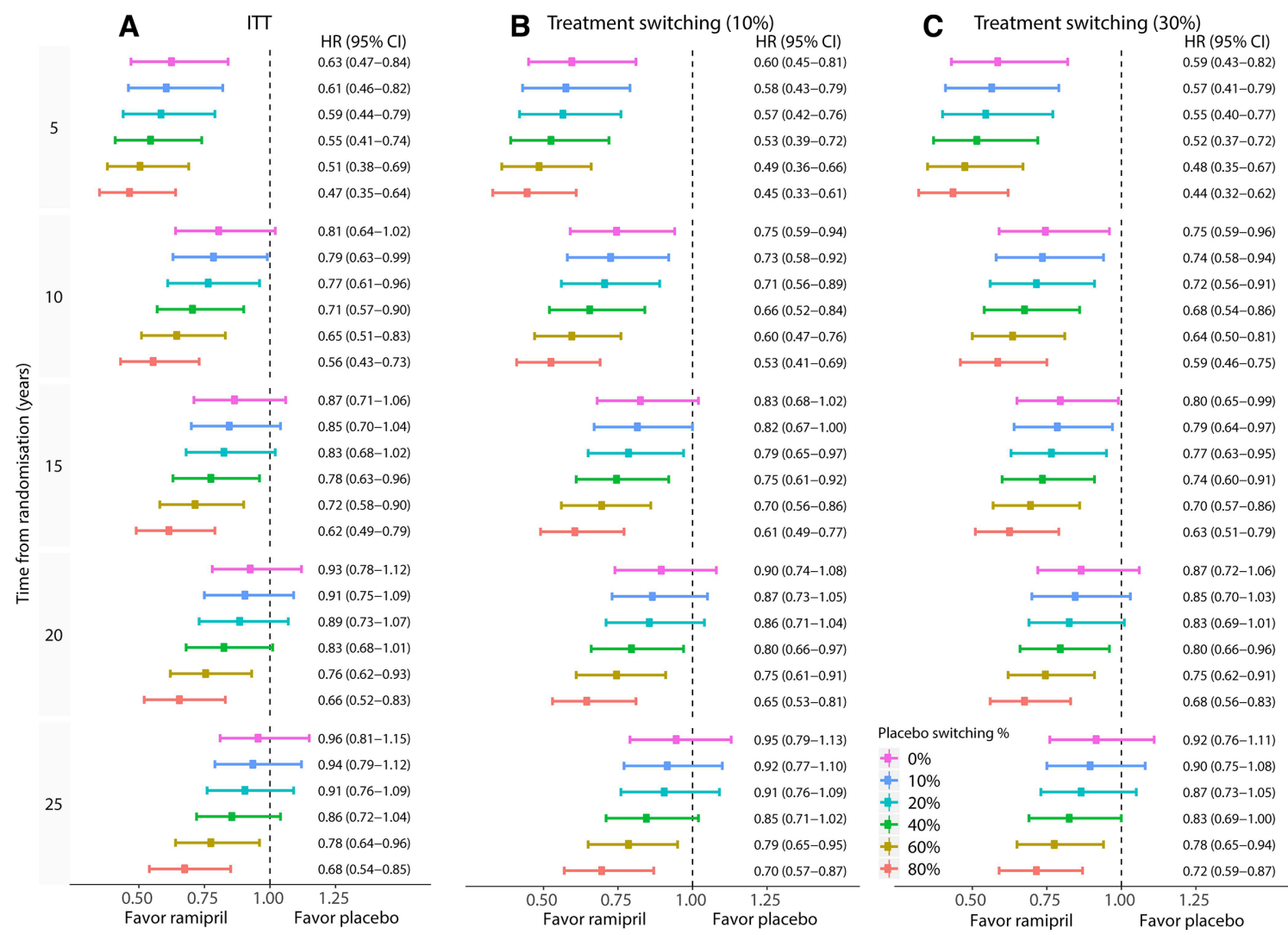

Figure 4 Adjusted HR from modelling of the dilution of the true treatment effect. Each scenario represents a proportion of patients in placebo arm switching to ramipril treatment. (A) Intention-to-treat (ITT) analysis for ramipril arm; (B) patients refused treatment in ramipril arm (10\%) were switched to placebo arm; (C) patients refused treatment or drug intolerance in ramipril arm (30\%) were switched to placebo arm.

Ramipril treatment improved life expectancy across all of the comorbidity groups studied, including diabetes (LED 32.1 vs 5.0 months), previous MI (20.1 vs 4.9 months), history of heart failure (19.5 vs 4.9 months), hypertension (16.6 vs 8.3 months), angina (16.2 vs 5.0 months) and was greater for patients aged $\geq 65$ years than $<65$ years (11.3 vs 5.7 months) (table 2 ). For all categorical time points from randomisation and all patient subgroups (except for Q-wave AMI at 25 years), there was an absolute and relative gain in life expectancy for ramipril (online supplementary tables 2 and 3). Moreover, for patients with diabetes, angina, previous heart failure and non Q-wave infarction, ramipril treatment demonstrated increasing benefit in life expectancy with increasing time from randomisation. For all other subgroups, the gain in life expectancy for ramipril group increased up to 15 years from the time of randomisation. In particular, ramipril treatment had a greater extension of life for patients with than without comorbidities, and was greatest for patients with diabetes (LED 32.1 months, $95 \% \mathrm{CI}-6.8$ to 71.0 ; LER $1.54,95 \%$ CI 0.9 to 2.61 ) (table 2).

The effect of patients in the placebo group who could have switched to ramipril treatment was assessed according to intention to treat with ramipril treatment switching at $10 \%$ (patients refusing treatment) and with ramipril treatment switching at $30 \%$ (patients refusing treatment or drug intolerances), and across placebo switching of $0 \%, 10 \%, 20 \%, 40 \%, 60 \%$ and $80 \%$. Ramipril treatment compared with placebo reduced mortality for all parameters of potential ramipril and placebo switching and at all time points to 25 years except for, $10 \%$ ramipril switching at 15 years with $0 \%$ placebo switching, at 20 years for $0 \%, 10 \%$ and $20 \%$ placebo switching, at 25 years for $0 \%, 10 \%, 20 \%, 40 \%$ placebo switching and for $30 \%$ ramipril switching at 20 years for $0 \%, 10 \%$ and $20 \%$ placebo switching, and at 25 years for $0 \%, 10 \%, 20 \%$ and $40 \%$ placebo switching (figure 4). If $80 \%$ of patients in placebo group had switched to ramipril treatment after study closure, the dilution of the true treatment was estimated to be up to $28 \%$, which would offer a maximum LED and LER of 33.6 months $(95 \%$ CI 28.4 to 38.9 ) and 1.81 (95\% CI 1.57 to 2.09) during the follow-up from randomisation. Similar results were identified when evaluated by exclusion of any patient who had refused or was intolerant of ramipril (online supplementary figure 1).

\section{DISCUSSION}

In this randomised study of the effect of ramipril treatment compared with placebo for patients with AMI and clinically defined heart failure followed up for nearly 30 years, we found that among 603 participants of the multicentre study, ramipril treatment was associated with substantial survival gains, which persisted beyond the blinded treatment allocation for up to 15 years. While the magnitude of the effect was greatest for patient with diabetes, it demonstrated a survival benefit for all comorbidity subgroups studied. Overall, for every day a patient received ramipril, on average, his/her life was extended by a further day.

Robust evidence supports the mortality benefit of ACE inhibition following AMI for patients with heart failure. ${ }^{1920}$ Moreover, international guidelines are clear in their recommendation for the prescription of ACE inhibitors following AMI. ${ }^{21}$ However, we are not aware of any study that has investigated the impact of ACE inhibition in patients with AMI and heart failure for longer than 12 years. ${ }^{22}$ Those studies which have studied ACE 
inhibition up to this time point have shown a beneficial effect in patients with heart failure ${ }^{23} 24$-a finding which our study builds on-but such studies have reported intention-to-treat effects without disclosing rates of drug switching between trial arms or estimating the potential resultant counterfactual survival times.

Our study found that ramipril had the greatest LED at about 15 years following the time from randomisation, and improved survival for the majority of combinations of switching of placebo and ramipril. Although the mortality benefit decreased over time, even after this period ramipril continued to convey a survival advantage, with a LER of 1.06 at final censorship at 29.6 years from time of randomisation. We acknowledge, however, that although the difference in median lifetime between that study arms was 14.5 months, the LED was smaller at 7.4 months and its lower confidence limit included the possibility of a negative effect. This was also reflected in the LER, which demonstrated a ratio $<1$ at the lower confidence limit. Therefore, although the point estimates for the effects of ramipril on long-term survival were very favourable, it is entirely plausible that the population parameter could lie at any position in the range.

We found that patients with diabetes, previous AMI, previous heart failure, hypertension and angina each benefited, on average, from ACE inhibition. These findings were upheld in sensitivity analyses according to period of censorship. Notably, the relative risk of survival for patients with diabetes was increased by $54 \%$, and supports other randomised evidence for the benefit of ACE inhibition in this population..$^{25}$ Nonetheless, we found that women had a worse LED with ramipril treatment. We cannot explain this, although given that this finding has not been supported in other randomised controlled trials the finding may be due to small sample size effects. Equally, patients with $\mathrm{Q}$ wave AMI appeared not to benefit in the long term from ramipril. However, for AIRE-S, we only tracked all-cause mortality and it is possible that ramipril reduced repeat AMI rather than improving left ventricular systolic function (and therefore survival) beyond the first year in this population.

In light of the enduring effect of ramipril, our study suggests that ramipril conveys early mechanistic effects which translate into favourable long-term clinical outcomes. Indeed, in 1994 the GISSI-3 (Gruppo Italiano per lo Studio della Sopravvivenza nell'infarcto Micardico) investigators hypothesised that the process of adverse ventricular remodelling may be permanently modified by just 1 month of treatment with an ACE inhibitor. ${ }^{26}$

\section{Key messages}

What is already known on this subject?

- ACE inhibition reduces mortality and morbidity in patients with heart failure after acute myocardial infarction (AMI); however, there are limited randomised data about the longterm survival benefits of ACE inhibition in this population.

\section{What might this study add?}

- This study demonstrates that treatment with ramipril for about 1 year, when started early post-AMI in patients with heart failure results in a survival benefit which is sustained over many years and offers, on average, an extension of life of an additional 1 year.

How might this impact on clinical practice?

- This study provided the evidence of long-term survival benefit of ACE inhibition in patients with heart failure after AMI.
The TRACE (Trandolapril Cardiac Evaluation) study investigators found median survival to be 4.6 years for those initially given placebo vs 6.9 years for those who had received up to 2 years of trandolapril. ${ }^{22}$ While our study corroborates these findings, we do not propose the discontinuation of ACE inhibition following myocardial infarction complicated by heart failure. Additionally, early survival may have enabled patients to be exposed to other treatments (such as intensive lipid-lowering therapy, mineralocorticoid receptor antagonists, beta-blockers, coronary revascularisation and cardiac rehabilitation), which may have become available after the end of the study and thus impacted favourably on their prognosis.

We recognised the limitations of this study. We were not able to establish which medications patients may have received or had taken after the end of the trial, which could have biased the results in those in the ramipril arm had they received ACE inhibition and/or contemporary secondary prevention therapies compared with patients in the placebo arm. However, we estimated a wide range of potential effects of ramipril switching and ramipril discontinuation, and found largely consistent results, as well as a potential underestimation of the impact of ramipril on survival by nearly a third. The use of RMST model could not account for the multitude of factors that could affect survival in both treatment arms over three decades including intercurrent illness, development of comorbidities, hospitalisations and changes in background medical therapy. We only had access to data for all-cause mortality, when ramipril may also have impacted on cardiovascular specific death and non-fatal major cardiovascular and cerebrovascular end points. In the 1993 AIRE study, the diagnosis of heart failure was made on clinical grounds and there was no further detailed classification based on left ventricular function and functional status. This therefore prevents further insights into the long-term impact of ramipril on survival in specific subgroups of patients according to these criteria. In addition, the lack of echocardiographic data at baseline, and reliance on a clinical diagnosis could have misclassified patients, and it is possible that some patients with clinical evidence of heart failure had preserved left ventricular systolic function. If this is the case, then our results support the notion of ACE inhibition for all patients with clinical heart failure following AMI.

Safety end points such as hypotension, worsening renal function and hyperkalaemia with ACIE therapy could not be captured. In 1993, for the AIRE study the diagnosis of heart failure was made on clinical grounds and while this could have misclassified patients, it is possible that some patients with clinical evidence of heart failure had preserved left ventricular systolic function and thus supports the notion of ACE inhibition for all patients with clinical heart failure following AMI.

In conclusion, this study demonstrates that treatment with ramipril for about 1 year, when started early post-AMI in patients with heart failure results in a survival benefit which is sustained over many years and offers, on average, an extension of life of an additional 1 year. These findings are evident across a range of patient groups studied and emphasise the importance of initiating treatment with ACE inhibition after AMI complicated by heart failure.

\section{Twitter Chris P Gale @cpgale3}

Acknowledgements The authors would like to acknowledge the contributions made to the original AIRE and AIREX studies. ${ }^{1011}$

Collaborators See AIRE and AIREX investigators. ${ }^{10,11}$ 
Contributors JW contributed to analysis, interpretation and drafted the manuscript; ASH contributed to conception and study design, data acquisition and interpretation and critically revised the manuscript; CPG contributed to conception and study design, interpretation and drafted the manuscript. All authors gave final approval and agreed to be accountable for all aspects of the work.

Funding The authors have not declared a specific grant for this research from any funding agency in the public, commercial or not-for-profit sectors.

Competing interests None declared.

Patient and public involvement Patients and/or the public were not involved in the design, conduct, reporting or dissemination plans of this research.

Patient consent for publication Not required.

Ethics approval This is a secondary analyses of long-term follow-up cohort, therefore an ethics approval is not required and patients were not involved in this study. The study complies with the Declaration of Helsinki.

Provenance and peer review Not commissioned; externally peer reviewed.

Data availability statement Data are available on reasonable request.

Open access This is an open access article distributed in accordance with the Creative Commons Attribution Non Commercial (CC BY-NC 4.0) license, which permits others to distribute, remix, adapt, build upon this work non-commercially, and license their derivative works on different terms, provided the original work is properly cited, appropriate credit is given, any changes made indicated, and the use is non-commercial. See: http://creativecommons.org/licenses/by-nc/4.0/.

\section{ORCID iD}

Jianhua Wu http://orcid.org/0000-0001-6093-599X

\section{REFERENCES}

1 Torabi A, Cleland JGF, Khan NK, et al. The timing of development and subsequent clinical course of heart failure after a myocardial infarction. Eur Heart $J$ 2008:29:859-70.

2 Ziaeian B, Fonarow GC. Epidemiology and aetiology of heart failure. Nat Rev Cardiol 2016;13:368-78.

3 Conrad N, Judge A, Tran J, et al. Temporal trends and patterns in heart failure incidence: a population-based study of 4 million individuals. Lancet 2018:391:572-80.

4 Koudstaal S, Pujades-Rodriguez M, Denaxas S, et al. Prognostic burden of heart failure recorded in primary care, acute hospital admissions, or both: a population-based linked electronic health record cohort study in 2.1 million people. Eur J Heart Fail 2017;19:1119-27.

5 Garg R, Yusuf S. Overview of randomized trials of angiotensin-converting enzyme inhibitors on mortality and morbidity in patients with heart failure. Collaborative group on ACE inhibitor trials. JAMA 1995;273:1450-6.

6 Yusuf S, Sleight P, Pogue J, et al. Heart outcomes prevention evaluation study, Investigators. Effects of an angiotensin-converting-enzyme inhibitor, ramipril, on cardiovascular events in high-risk patients. N Engl J Med 2000;342:145-53.

7 Fox KM. European trial on reduction of cardiac events with perindopril in stable coronary artery disease Investigators. efficacy of perindopril in reduction of cardiovascular events among patients with stable coronary artery disease: randomised, double-blind, placebo-controlled, multicentre trial (the EUROPA study). Lancet 2003:362:782-8.

8 Ambrosioni E, Borghi C, Magnani B. The effect of the angiotensin-converting-enzyme inhibitor zofenopril on mortality and morbidity after anterior myocardial infarction. the survival of myocardial infarction long-term evaluation (SMILE) study Investigators. $N$ Engl J Med 1995;332:80-5.
9 Pfeffer MA, Braunwald E, Moyé LA, et al. Effect of captopril on mortality and morbidity in patients with left ventricular dysfunction after myocardial infarction. Results of the survival and ventricular enlargement trial. The SAVE Investigators. N Engl J Med 1992;327:669-77.

10 The acute infarction ramipril efficacy (AIRE) study Investigators. Effect of ramipril on mortality and morbidity of survivors of acute myocardial infarction with clinical evidence of heart failure. Lancet 1993;342:821-8.

11 Hall AS, Murray GD, Ball SG. Follow-Up study of patients randomly allocated ramipril or placebo for heart failure after acute myocardial infarction: AIRE extension (AIREX) study. acute infarction ramipril efficacy. Lancet 1997;349:1493-7.

12 Hall AS, Winter C, Bogle SM, et al. The acute infarction ramipril efficacy (AIRE) study: rationale, design, organization, and outcome definitions. J Cardiovasc Pharmacol 1991;18 Suppl 2:S105-9.

13 Royston P, Parmar MKB. The use of restricted mean survival time to estimate the treatment effect in randomized clinical trials when the proportional hazards assumption is in doubt. Stat Med 2011;30:2409-21.

14 Gregson J, Sharples L, Stone GW, et al. Nonproportional Hazards for Time-to-Event Outcomes in Clinical Trials: JACC Review Topic of the Week. J Am Coll Cardiol 2019;74:2102-12.

15 Dehbi H-M, Royston P, Hackshaw A. Life expectancy difference and life expectancy ratio: two measures of treatment effects in randomised trials with non-proportional hazards. BMJ 2017;357:j2250.

16 Li G, Tiwari RC, Wells MT. Quantile comparison functions in two-sample problems, with application to comparisons of diagnostic markers. J Am Stat Assoc 1996;91:689-98

17 Robins JM, Tsiatis AA. Correcting for non-compliance in randomized trials using RANK preserving structural failure time models. Commun Stat Theory Methods 1991:20:2609-31.

18 White IR, Babiker AG, Walker S, et al. Randomization-based methods for correcting for treatment changes: examples from the Concorde trial. Stat Med 1999;18:2617-34.

19 Køber L, Torp-Pedersen C, Carlsen JE, et al. A clinical trial of the angiotensinconverting-enzyme inhibitor trandolapril in patients with left ventricular dysfunction after myocardial infarction. trandolapril cardiac evaluation (trace) Study Group. N Engl J Med 1995;333:1670-6.

20 Pfeffer MA, Greaves SC, Arnold JM, et al. Early versus delayed angiotensin-converting enzyme inhibition therapy in acute myocardial infarction. The healing and early afterload reducing therapy trial. Circulation 1997;95:2643-51.

21 Ibanez B, James S, Agewall S, et al. 2017 ESC guidelines for the management of acute myocardial infarction in patients presenting with ST-segment elevation: the task force for the management of acute myocardial infarction in patients presenting with ST-segment elevation of the European Society of cardiology (ESC). Eur Heart J 2018;39:119-77.

22 Buch P, Rasmussen S, Abildstrom SZ, et al. The long-term impact of the angiotensinconverting enzyme inhibitor trandolapril on mortality and hospital admissions in patients with left ventricular dysfunction after a myocardial infarction: follow-up to 12 years. Eur Heart J 2005;26:145-52

23 Swedberg K, Kjekshus J, Snapinn S. Long-Term survival in severe heart failure in patients treated with enalapril. ten year follow-up of consensus I. Eur Heart $J$ 1999:20:136-9.

24 Jong P, Yusuf S, Rousseau MF, et al. Effect of enalapril on 12-year survival and life expectancy in patients with left ventricular systolic dysfunction: a follow-up study. Lancet 2003:361:1843-8.

25 Heart Outcomes Prevention Evaluation Study Investigators. Effects of ramipril on cardiovascular and microvascular outcomes in people with diabetes mellitus: results of the hope study and MICRO-HOPE substudy. The Lancet 2000;355:253-9.

26 Miocardico Nell'Infarto. Six-Month effects of early treatment with lisinopril and transdermal glyceryl trinitrate singly and together withdrawn six weeks atter acute myocardial infarction: the GISSI-3 trial. J Am Coll Cardiol 1996;27:337-44. 